\title{
LEGITIMAÇÃO PELO PROCEDIMENTO E CONTROLE DAS EMOCÕES: NOVOS PARADIGMAS DO ESPORTE E LAZER NO SISTEMA NACIONAL DE ESPORTE E LAZER
}

DOI: 105902/0102830819481

Data de Submissão: 13/09/2015

Data de Aprovação: 20/10/2015

\section{Carlos Luiz Cardoso}

c.cardoso@ufsc.br

Universidade Federal de Santa Catarina

RESUMO: A presente pesquisa procura fundamentações para o sistema nacional de esporte e lazer e suas políticas públicas no contexto contemporâneo, ressignificando-o mediante a presença dos conceitos legitimação pelo procedimento de Luhmann, paradigma de Kuhn e controle das emoções de Elias. Amplia-se a compreensão dos eventos esportivos, tanto em níveis de complexidade quanto em territorialidade, mediante a observação de três eventos esportivos: Jogos brasileiros universitários (nacional), jogos sulamericanos (regional) e jogos intercurso (local). Os resultados apontam para a constatação de instâncias deliberativas e disciplinares dos eventos usadas como sistema de controle das emoções. Tais encaminhamentos no interior do esporte garantem tanto a legitimação do evento quanto a sustentação da vida dos sistemas esportivo e social, via procedimento e auto-aprendizagem sistêmica. Diante da constatação do processo civilizatório, indicamos novas temáticas na "formação" de professores.

Palavras-chave: Teoria dos sistemas; Competição esportiva; Controle das emoções; Legitimação de condutas. 


\section{Problematização}

Poucas são as intervenções realizadas no interior do sistema esportivo, levando em consideração as novas compreensões da Teoria dos Sistemas (Bracht, 1997), também como são poucas as intervenções nesse mesmo campo/sistema, levando em consideração as novas compreensões simbólicas, tendo como eixo de análise o 'controle das emoções' que o esporte proporciona (Elias e Dunning, 1992) e não menos importante seria compreender como o esporte se legitima nesse novo ponto de vista da Teoria dos Sistemas (Luhmann, 2009; Neves e Samios, 1997), bem como se o que ocorre dentro dele é legítimo (Luhmann, 1980).

Portanto, diante do exposto, justifica-se este estudo no sentido de acompanhar, registrar e estudar para melhor compreender o sistema esportivo na realidade brasileira (Macedo, 2006), considerando os vários níveis e instâncias das decisões, que em conjunto, orientam as políticas públicas nesse campo da 'expressividade humana' (Reichold, 2006) e/ou 'cultura de movimento' (Kunz e Trebels, 2006; Kunz, 2000). Tais sistemas se especializam e a compreensão serve para acompanhar o processo de desenvolvimento, de modo que nossa pesquisa procura compreender, mas não procura julgar e a compreensão serve como uma terceira condição de observação para além dos códigos binários (visão global/visão parcial) e que Luhmann (1997) vai chamar de observação de terceira ordem, diferente das observações precedentes de segunda ordem.

\section{A Nova Teoria de Sistemas}

Num esforço acadêmico profundo, Luhmann recupera, por um lado, as origens da Teoria de Sistemas de Bertalanfy do campo da biologia, onde emergiu a cibernética e por outro lado, as reflexões de Maturana e Varela (1995) recuperam aspectos relacionados à evolução dos organismos vivos, também no campo da biologia, onde emergiu a concepção autopoiesis, de modo que é dessa tarefa, não pouco árdua, que elabora-se então uma teoria sociológica universal e para isso 
realiza-se uma passagem para a atual teoria sistêmico-funcional que diferencia sistema de ambiente.

Para Luhmann (2009), nossa sociedade moderna se caracteriza pela diferenciação funcional e isso leva ao estudo de tais complexidades sistêmicas que se especializam no interior do próprio sistema. Assim ele passa a dizer que a sociedade contemporânea não mais pode ser compreendida pelas 'velhas' teorias da hierarquização, mas sim pelas 'novas' funções diferenciadas que se encontram em atividade circulatória, porém com diferenciações de diversos níveis.

\subsection{Sistemas: vital, psíquico e social}

Luhmann (apud Neves e Samios, 1997, p. 16s) apresenta distintamente os três tipos fundamentais de sua teoria de sistemas que se autorreferem entre si, no entanto não perdem suas especificidades. O primeiro deles são os sistemas vivos (ou sistema vital), que se referem às operações vitais dos organismos vivos e suas correspondentes formas de auto-organização da vida; o segundo são os sistemas psíquicos (ou sistema psicológico), que se refere à consciência e os modos de operação desses estados psíquicos, estados de consciência ou o 'modo-de-ser'; e por último, são os sistemas sociais (ou de comunicação), que se referem aos processos de seleção/distinção, onde se encontram a informação, a comunicação e a compreensão e aqui temos como importante as condições nas quais se dão as comunicações, que tanto podem ser de consenso como dissenso, pois como diz Watzlawick (2005), 'é impossível não se comunicar'.

Por isso que para Niklas Luhmann o sistema social é composto de comunicação e não de pessoas. As pessoas, pelo que se vê, estão no sistema psíquico, em função dos papéis e da personalidade. Só um sistema que produz pensamento, como o sistema psíquico poderia ter como ambiente a pessoa/o indivíduo, pois é por aí que estamos vinculados à consciência, que tanto produz pensamento como permite reconhecer os pensamentos legítimos dos ilegítimos. Esses sistemas que se autorreferem também podem ser chamados de autopoiéticos. 


\subsection{Sistemas autopoiéticos}

Todo sistema vivo, segundo Maturana e Varela (1995), é caracterizado como um organismo vivo que se autoproduz, ou seja, que se produz a si mesmo. A palavra poien (produzir) vem do grego, assim como auto (mesmo). Sendo essa a característica principal, Luhmann se apropria dessa concepção, a partir dos organismos vivos como sistemas, e elabora uma passagem para os demais sistemas, pois para ele, significa que cada um desses sistemas (vivo, psíquico ou social) tem a capacidade de elaborar a partir de si mesmo a sua estrutura e os elementos que o compõem, promovendo constantemente e continuamente a sua própria constituição.

Diante desse quadro teórico, vamos nos aproximar do sistema esportivo como uma especialização das manifestações da cultura de movimento e da corporeidade, como subespecializações no interior do campo de conhecimento da educação física brasileira.

Sistemas esportivos necessitam de um ambiente onde possam se manifestar, que são os jogadores/atletas, pois o sistema social também necessita de pessoas/ indivíduos como ambiente. Sendo assim, vamos perceber que sistema e ambiente são distintos, tanto que os sistemas são 'irritados' pelo ambiente, ou seja, o atleta/jogador 'irrita' o sistema esportivo, para que esse busque soluções no seu próprio interior. Com essa possibilidade de continuidade e constância, os sistemas esportivos ganham complexidades como também aumentam a complexidade do ambiente. Em ambos, a necessidade de redução de complexidade só é possível com o aumento da compreensão da comunicação e da informação, o que se torna, automaticamente, um aumento da complexidade. Portanto, se reduz complexidade quando se eleva a compreensão da complexidade, isso tanto vale para os sistemas como para os ambientes. 


\subsection{Legitimação}

Luhmann (1980) analisa, em sua obra Legitimação pelo procedimento, de 1969, a legitimidade do processo, que "vai do ponto inicial do procedimento de tomada de decisão até à própria decisão tomada" (p. 4). Dessa forma, é o tal procedimento aquele que confere legitimidade e não qualquer uma das partes componentes. Estes sistemas de ação, que o autor chama de procedimento, proporcionam àqueles que dele dependem, a aprender a aceitar uma decisão que vai ocorrer, antes de sua ocorrência. Sendo assim, os interessados no resultado, se vêem na contingência de assumi-la, sem contestá-la, ainda que sejam desfavoráveis ao resultado.

Existe um controle inicial para que aos poucos se vá criando as condições para a aceitação de uma decisão final. Essa função legitimadora do procedimento não está aí para produzir consenso entre as partes, mas sim para que se tornem inevitáveis e prováveis decepções em decepções difusas, ou seja, mesmo que haja descontentes, as partes aceitam a decisão. Estamos diante de algo onde a função legitimadora do procedimento não está existindo para substituir uma decepção por um reconhecimento, mas sim para imunizar, reduzir, minimizar a decisão final contra as decepções inevitáveis. Tanto a Teoria dos Sistemas de Luhmann (2009) como a Teoria das Configurações de Elias e Dunning (1992) servem, por um lado, para descrições do funcionamento dos sistemas e as compreensões das 'irritações' promovidas pelo ambiente, e por outro lado, servem para o exercício do 'controle das emoções' como um processo de aprendizagem que caracteriza o processo civilizatório de longuíssima duração.

Ao pegarmos estes princípios e fundamentos da legitimação pelo procedimento ('irritação' e 'controle das emoções'), encontraremos no interior do sistema esportivo uma série de exemplos que poderiam confirmar tais caracterizações. Nem sempre o atleta/jogador atinge o sucesso ou o êxito esportivo, também aqueles que acompanham o processo, ou seja, o jogo ou a competição, nem sempre têm o 
resultado final a favor de suas expectativas. A decepção é inevitável, no entanto se pode ver aí refletida uma série de justificativas para ofuscar a decepção, contando com inúmeras minimizações da ação/gesto técnico, motivos de treinamento, preparação da equipe e outras considerações comumente utilizadas.

Esta aprendizagem ou controle das emoções, garantidas pelo processo de legitimação pelo procedimento, ganha continuidade em todos os subsistemas na sociedade moderna e complexa. Exemplo próximo, como diria Elias e Dunning (1992), faz parte dos estudos da sociologia do esporte, onde, principalmente Elias (1998), quando destaca as novas possibilidades de sínteses transgeracionais, aponta sua teoria das configurações como aquela que possibilitaria compreender tais manifestações somente quando o ser humano pudesse vir a conceber uma unificação das dimensões através desse mesmo processo de aprendizagem. Aquela do espaço e essa do tempo; aquela como a terceira e essa como a quarta dimensão respectivamente, naquilo que ele denomina de uma nova dimensão espaço-temporal chamada de quinta dimensão simbólica. Este símbolo que só a humanidade como unidade poderia vir a conceber em forma de cultura, permitiria compreender o esporte como um fenômeno da sociedade moderna, com início na Revolução Industrial e que traz consigo um alargamento da concepção de tempo, tanto cronológico, linear e horizontal, como kairológico, interior e vertical.

\subsection{Esporte e Lazer}

A origem da palavra esporte/desporto nos leva, segundo Elias e Dunning (1992), por um lado à palavra inglesa sport, que ao ser adotada em vários outros países e continentes, se caracterizaria como um passatempo. Para os autores essa adoção em outras culturas nem sempre foi clara e imediata, dado que na Alemanha, até final de século XX ainda não se traduzia facilmente, tanto a palavra sport como a palavra gentleman. Por outro lado, a palavra francesa desport quer dizer prazer ou diversão. No entanto, seguindo suas origens, encontramos sport como uma palavra inglesa formada do antigo francês desport. 
Vimos acima que tanto aquilo que gostaríamos que fosse esporte ou que fosse lazer, tem uma mesma e única origem, ou seja, é com a Revolução Industrial que se cunha os significados simbólicos dessas palavras para designar estados ou condutas. Tanto uma como outra tornaram-se subsistemas vinculados à aprendizagem das novas noções espaço-temporais que a humanidade desenvolveu a partir desse fenômeno característico da sociedade moderna.

Internamente o sistema esportivo foi se especializando e legitimando seu procedimento através de eventos, torneios, campeonatos, formações de clubes, associações e coisas do gênero. Por outro lado, o sistema de lazer fica preso, no nosso entender, ao subsistema do mundo do trabalho e assim se constituindo numa dicotomia denominada 'tempo de trabalho versus tempo livre'.

A especialização do sistema esportivo acompanhou as exigências do controle do ambiente esportivo, com sofisticações quanto ao controle do espaço e do tempo, percebidos no modelo dos Jogos Olímpicos e suas derivações. Por outro lado, a especialização do sistema de lazer acompanhou as exigências das organizações das cidades e seus ambientes 'naturais' para práticas de lazer, atividade física, exercícios e jogos em geral. No entanto essa especialização, teoricamente ainda está fortemente vinculada em só ser compreendida quando comparada com a especialização do tempo de trabalho, o que nos parece de imediato uma incongruência.

Tanto o mundo do trabalho quanto o mundo do lazer são regidos por novas concepções espaço-temporais, no entanto as teorias sociológicas, conforme esclarecem Elias e Dunning (1992), não acompanharam ou não se debruçaram o suficiente para essa nova compreensão e mudança de paradigma espaço-tempo.

\subsection{Paradigmas}

Para Kuhn (2006, p. 23s), existe uma distinção entre dois tipos de desenvolvimento científico: o normal e o revolucionário. Para o autor a grande maioria das pesquisas se encontra no primeiro paradigma, ou seja, é uma produção de conhecimento que 
se adapta ao que já está crescendo como acervo científico e se denomina como concepção cumulativa. Por outro lado, o mesmo autor diz que o desenvolvimento científico também se compreende de um modo não-cumulativo, mas nesse caso as pistas são mais sutis e únicas e que, portanto, podem ser chamadas também de revolucionárias. Estas exigem a mudança no modo de pensar para que possam ser assimiladas. Essas descobertas podem ser denominadas como 'invenção', 'inovação' e 'criatividade'.

\section{Referenciais metodológicos}

Nossa pesquisa opta metodologicamente pelo estudo descritivo-exploratório que ousa tentar dar os primeiros passos em direção a um possível caminho de busca e compreensão do sistema esportivo e de lazer, sabendo que não é o único, mas que pode ser uma chance de entendimento. A opção metodológica pelo processo interpretativo, segundo Stein (2000), permite a ampliação da compreensão humana, motivo pelo qual os sistemas (sociais, psíquicos e vitais) ganham e reduzem complexidade. Segundo o autor, a hermenêutica técnica é usada na abordagem de textos; a hermenêutica filosófica tem pretensões onde procura alcançar problemas ligados ao conhecimento, como em outros tempos se encontrava a dialética; e por último, portanto nossa opção e aproximação com a filosofia hermenêutica é produto do século $X X$, introduzindo um novo modo de conceber o próprio conceito de compreensão e interpretação.

Diante de tais colocações e diferentes modos de aproximação com o mundo cotidiano dos sistemas de esporte e lazer, nos permite conceber que nossa aproximação a tais sistemas investigados permitem novos 'modo-de-ser', tanto nas situações do cotidiano como no 'se-movimentar' no interior do sistema esportivo. Diante disso, procuramos acompanhar eventos esportivos, nos mais diversos níveis e instâncias, para estudar as instâncias e as formas de decisão, quando está em jogo a conduta do ser humano no interior do sistema esportivo e as legitimações dessa cultura de movimento, indicando as respectivas dimensões 
e níveis técnicos de decisão que podem proporcionar mudanças paradigmáticas em forma de 'inovação/invenção' tanto tecnológica quanto fenomenológica.

De acordo com o objetivo do projeto procuramos abordar os Conselhos e Tribunais de Justiça Desportiva do evento correspondente, em todos os seus níveis de abrangência territorial. Para isso acompanhamos eventos esportivos, nos mais diversos níveis e instâncias deliberativas, tendo como ambientes de investigação: 1) Jogos Internos do Curso de Educação Física - JINEF; 2) Jogos Universitários Brasileiros (Exemplo: Campeonato Brasileiro de Futebol Masculino); e 3) Jogos Regionais-Sul (Exemplo: Copa UniSINOS). A partir desses eventos, dirigimos a atenção para os Boletins dos Jogos, onde se encontravam as decisões e orientações da Comissão Organizadora e de Recursos Técnicos e Jurídicos, bem como das decisões e análise de condutas esportivas dos atletas pelo Tribunal de Justiça Desportiva. Foram utilizados na pesquisa os recursos de áudio e vídeo do Núcleo de Estudos Pedagógicos em Educação Física - NEPEF e do Laboratório de Mídia - LaboMídia.

\section{Discussão de resultados}

Nos Jogos Brasileiros Universitários de Futebol de Campo Masculino, nível nacional, a Comissão Organizadora, informou durante o Congresso Técnico, que a Comissão disciplinar seria o próprio Tribunal de Justiça Desportiva do estado organizador do evento. De modo que qualquer irregularidade, exclusive aquelas constantes do Regulamento Geral (seriam encaminhadas a este Tribunal), e os trâmites a seguir são do conhecimento das Instituições de Ensino Superior do país, inscritas no campeonato.

Já na Copa UniSINOS - Jogos do MERCOSUL, a Comissão Disciplinar é o próprio órgão da Justiça Desportiva e tem caráter sumaríssimo, sendo formada por três integrantes nomeados pela Comissão Organizadora. Aqui os protestos, sobre qualquer infração ao regulamento, deverão ser encaminhados pelas instituições à Comissão Organizadora até meia hora a contar da prova ou do jogo, cabendo 
exclusivamente ao reclamante apresentação das provas que alegar. A instituição que incluir em sua representação qualquer atleta não-universitário ou com situação irregular de matrícula, será desclassificada do evento na modalidade em questão, perdendo o valor da caução. As equipes participantes desta competição se obrigam a observar as disposições deste regulamento, como as demais resoluções estabelecidas.

Para finalizar, nos Jogos Internos da Educação Física - JINEF’s, a Comissão Disciplinar é formada por um professor, juntamente com um acadêmico e um terceiro integrante a ser escolhido no Congresso Técnico que representará os participantes em geral.

Todos os recursos e denúncias que não estiverem devidamente assinados por um dos representantes será recebido pela CCO - Comissão Central Organizadora, porém encaminhados para a Comissão Disciplinar como "não conhecido recurso ou denúncia”. Destaca também que os recursos e denúncias deverão ser escritos de forma legível e coerente, explicando os motivos do mesmo e que para esse encaminhamento a equipe deverá pagar o valor de $\mathrm{R} \$ 30,00$ (trinta reais). Observamos que, no que se referem às questões disciplinares, os árbitros deverão comparecer sempre que necessário à CCO para prestar esclarecimentos técnicos e disciplinares possivelmente ocorridos em jogos ou fora deles.

\section{Legitimação, esporte e paradigmas}

Todas as competições esportivas, por um lado, buscam 'controlar as emoções', que por estarem em desacordo ao previsto, apresentando condutas indisciplinadas, acabam colocando uma 'pequena' penalidade, tanto para o infrator como para aquele que busca 'justiça'. No primeiro caso (UniSINOS), destaca-se uma caução (de grande valor para o tipo evento, inclusive) e a apresentação das provas, no caso de denúncia, por escrito. No caso dos JINEF's, constata-se uma taxa (de pequeno valor, pois aqui o evento é realizado entre estudantes) e também a apresentação de provas, no caso de denúncia, por escrito. 
Já por outro lado, é no interior da própria Comissão Organizado que se encontram as Comissões Disciplinares (UniSINOS e JINEF's), no entanto no caso da CBDU a Comissão Disciplinar é o próprio Tribunal de Justiça Desportiva do estado que realiza a competição.

Embora os níveis e instâncias das competições sejam distintos (local, nacional e sul-americano), as preocupações com questões disciplinares e condutas esportivas são tratadas pelos mesmos princípios jurídicos: a) controlar as condutas inadequadas, tendo como 'ferramentas' o próprio Regulamento Geral (estar ciente dele); as Comissões Disciplinares (protestos, reclamações e denúncias); e a Arbitragem (de forma imediata, no próprio jogo ou fora dele, antes ou depois dos jogos); e b) criar uma forma de penalização (taxas, por exemplo), para quem levante suspeitas, fazendo uma denúncia, demonstrando que nem os Árbitros, nem a Comissão Disciplinar e nem o Regulamento Geral, através da realização do Congresso Técnico, conseguiu perceber tal irregularidade.

Essas constatações vão ao encontro das já comentadas especializações dos sistemas em sub-sistemas, dado que as 'irritações' provocadas pelo ambiente (aqui é esportivo - conduta dos atletas) provocam os sistemas de organização dos eventos. Assim, o sistema sofre perturbações, e para se defender, já cria de antemão, as possíveis defesas, prevendo possíveis procedimentos.

Fica assim legitimado o processo pelo qual os procedimentos dão sustentação e eventos dessa natureza ocorrem, mesmo que não aconteça o que já estava previsto. Se por acaso ocorrer, também já fica legitimado, pois esta pré-visão de organização de sistemas conta com uma aprendizagem ocorrida nos demais eventos esportivos que a antecederam e já vai preparando possíveis mudanças de atitudes, condutas e comportamentos para os futuros eventos.

\section{Consequências e reflexões didático-pedagógicas}

Como vimos acima, nosso mundo contemporâneo passa a ser denominado de 'sociedade complexa' que se especializa nas funções, dentro dos próprios sistemas, 
como subssistemas. Não se pode mais compreender tais complexidades pelas 'velhas' teorias da hierarquização, mas sim pelas 'novas' funções diferenciadas que se encontram em atividade circulatória, porém em diferentes níveis.

Embora as competições se apresentem em níveis distintos (subssistemas territoriais), o sistema geral ao qual pertencem prende-se às Instituições de Ensino Superior (formação de professores/profissionais da Educação Física atletas e/ou técnicos e preparadores físicos). Nesse caso ocorre uma passagem que, além do fato de pertencer ao sistema competitivo, pertencem também ao sistema educativo. Esta diferenciação dos sistemas de ação que chamamos de procedimento proporciona àqueles que dele participam, de uma aprendizagem, pois passam a aceitar as decisões que vai ocorrer, antes de sua ocorrência (auxiliados pelos regulamentos).

Essa função legitimadora do procedimento existe para imunizar, reduzir ou minimizar a decisão final contra as decepções inevitáveis. Pois como dissemos anteriormente, tanto taxas como caução serve para reduzir ou minimizar o 'ingresso de protestos e denúncias contra condutas indisciplinadas e/ou antidesportivas'. Tanto a Teoria dos Sistemas de Luhmann como a Teoria das Configurações de Elias servem, por um lado, para descrições do funcionamento dos sistemas e as compreensões das 'irritações' promovidas pelo ambiente, e por outro lado, servem para o exercício do 'controle das emoções' como um processo de aprendizagem que caracteriza o processo civilizatório de longuíssima duração.

O que acabamos de ver, em forma de sínteses transversais, geradas por entrelaçamento de sistemas, possibilita novas compreensões do ser humano (professores, profissionais e acadêmicos), para conceber uma unificação das dimensões através de um mesmo processo de aprendizagem. Tanto o espaço como o tempo; tanto a tridimensionalidade como a quadrimensionalidade (como níveis distintos), passariam a proporcionar outra dimensão, naquilo que denominamos como nova dimensão espaço-temporal simbólica. Símbolo esse que só a humanidade como unidade poderia vir a conceber em forma de cultura, 
e permitiria compreender o esporte como um fenômeno da sociedade moderna, e que trazendo consigo um alargamento da concepção de tempo, tanto cronológico, linear e horizontal, como kairológico, interior e vertical.

A especialização do sistema esportivo acompanhou as exigências do modelo dos Jogos Olímpicos e suas derivações. Por outro lado, a especialização do sistema de lazer acompanhou as exigências das organizações das cidades e seus ambientes 'naturais' para práticas de lazer, atividade física, exercícios e jogos em geral. E mais, a especialização no mundo da pesquisa, e por derivação, no mundo do ensino, têm proporcionado mudanças paradigmáticas que exigem, não só um tempo como também um esforço para que possam ser compreendidas em seu próprio interior por seus 'pares'.

Esforço no desenvolvimento científico compreende-se, por um lado, de modo cumulativo, e por outro, de modo revolucionário. Nesse segundo caso as pistas são mais sutis e únicas e que, portanto, podem ser chamadas também de 're-evolucionárias'. Exigem a mudança no 'modo-de-pensar' para que possam ser assimiladas, pois são descobertas denominadas como 'invenção', 'inovação' e 'criatividade' e que a nova Teoria de Sistemas, como teoria universal, poderia estar proporcionando passos num longo ‘caminho' transgeracional. 


\section{Referências}

BRACHT, V. Sociologia crítica do esporte: uma introdução. Vitória: EdUFES, 1997.

ELIAS, N. Sobre o tempo. Trad. Vera Ribeiro. Rio de Janeiro: Jorge Zahar, 1998.

ELIAS, N. e DUNNING, E. A busca da excitação. Trad. Maria Silva. Lisboa: Difel, 1992. (Coleção Memória e Sociedade).

KUHN, Th. S. O caminho desde A Estrutura: ensaios filosóficos, 1970-1993, com uma entrevista autobiográfica. Trad. César Mortari. São Paulo: UNESP, 2006.

KUNZ, E. Esporte: uma abordagem com a fenomenologia. Revista Movimento, Porto Alegre, ano 6, n. 12, 2000.

KUNZ, E. e TREBELS, A. H. (Orgs.). Educação Física Crítico-emancipatória: com uma perspectiva da pedagogia alemã do esporte. ljuí: Unijuí, 2006. (Coleção Educação Física).

LUHMANN, N. Introdução à Teoria dos Sistemas: aulas publicadas por Javier T. Nafarrate. Trad. Ana C. A. Nasser. Petrópolis: Vozes, 2009. (Coleção Sociologia). Conhecimento como construção. In: NEVES, C. E. B. e SAMIOS, E. M. B. (Orgs.). Niklas Luhmann: a nova Teoria dos Sistemas. Trad. Eva M. B. Samios. Porto Alegre: EdUFRGS/Goethe-Institute/ICBA, 1997, p. 92-111. (Coleção Diálogos Brasil-Alemanha nas Ciências Humanas, v. 9).

Legitimação pelo procedimento. Trad. Maria Corte-Real. Brasília: UnB, 1980. (Coleção Pensamento Político, v. 15).

MATURANA, [Romesín], H. \& VARELA, Francisco J. A árvore do conhecimento: as bases biológicas da compreensão humana. Campinas: Editorial Psy, 1995. [Original de 1984]. 
NEVES, C. E. B. e SAMIOS, E. M.. B. (Orgs.). Niklas Luhmann: a Nova Teoria dos Sistemas. Trad. Eva M. B. Samios. Porto Alegre: EdUFRGS/Goethe-InstitutICBA, 1997. (Diálogos Brasil/Alemanha Ciências Humanas, v. 9).

REICHOLD, A. A corporeidade esquecida: sobre o papel do corpo em teorias ontológicas. Trad. Benno Dischinger. São Leopoldo: Nova Harmonia, 2006.

STEIN, E. Interpretacionismo: a tradição hermenêutica diante de duas novas propostas. In: REIS, R. R. e ROCHA, R. P. (Orgs.). Filosofia hermenêutica. Santa Maria: UFSM, 2000.

WATZLAWICK, P. A Pragmática da Comunicação Humana: definição dos modelos e conceitos de base. Disponível em: <http://w3.ualg.pt/ farinha/activ_ docente/psic_comunic/projeccoes/modelobase>. Acesso 21 março 2005. (MRI - Mental Research Institute - Grupo de Palo Alto). 


\title{
Legitimation by Procedure and Control of Emotions: \\ New Paradigms of Sports and Recreation in the National Sporting and Recreation System
}

\begin{abstract}
This research seeks foundations for the national system of sport and recreation and public politics in the contemporany context, giving new meaning to it by the presence of the concepts of legitimacy procedure by Luhmann, paradigm by Kuhn and control of emotions by Elias. It broadens the understanding of sports events, both in levels of complexity as in territoriality, by observing three sporting events: Brazilian university games (national); the south american games (regional) and intercourse games (local). The results point to the realization deliberative and disciplinary bodies of the events used as emotions control system. Such referrals within the sport both guaranteed the legitimacy of the event as the life support of sporting and social systems, via procedure and systemic self-learning. Before the conclusion of the civilizing process, we indicate new themes in the "training" of teachers.
\end{abstract}

Keywords: Systems theory. Sports competition. Control of emotions. Legitimization of conduct.

\section{Legitimación por Procedimiento y Control de las Emociones: Nuevos Paradigmas de los Deportes y la Recreación en el Sistema Nacional del Deporte y la Recreación}

Resumen: Esta investigación busca bases para el sistema nacional del deporte y la recreación y las políticas públicas en el contexto contemporáneo, dando un nuevo significado a la misma por la presencia de los conceptos de legitimidad por procedimiento Luhmann, paradigma de Kuhn y el control de los sentimientos de Elias. Se amplía la comprensión de los eventos deportivos, tanto en niveles de complejidad como en la territorialidad, mediante la observación de tres eventos deportivos: juegos brasileños universitarios (nacionales), los juegos sudamericanos (regionales) y juegos entre cursos (local). Los resultados apuntan 
a la deliberación y constatación del órganos disciplinarios de los eventos como sistema de control de lãs emociones. Tales referencias dentro del deporte tanto garantizan la legitimidad del evento como el apoyo a la vida de los sistemas deportivos y sociales, a través de procedimiento y el autoaprendizaje sistémica. Antes de la conclusión del proceso de civilización, indicamos nuevos temas en el "entrenamiento" de los docentes.

Palabras clave: Teoría de sistemas. La competencia deportiva. El control de las emociones. Legitimación de conducta. 